\title{
O Iluminado: o gênero do horror na leitura de Stanley Kubrick
}

Helvio Moraes ${ }^{1}$

\section{Resumo}

Este artigo tem por objetivo investigar a leitura que Kubrick faz do gênero do horror, seja pela literatura, onde busca a fonte para o roteiro de seu filme, seja pelo diálogo que estabelece com outras produções cinematográficas do gênero. Partindo dos pressupostos de Fredric Jameson, Mikhail Bakhtin, e de estudiosos da obra do cineasta, como Randy Rasmussen, Mario Falsetto, Roberto Romano, Maria Sylvia Franco, entre outros, percebemos que, através do procedimento metagenérico - que esquiva-se de uma postura convencional, pela reflexão sobre a estrutura genérica que toma como objeto -, assim como pelo recurso a um elemento elíptico, Kubrick propõe uma inovação e um novo sentido para o gênero.

Palavras-chave: Gênero do horror; Gótico; Literatura e cinema

\begin{abstract}
:
This article aims at investigating Stanley Kubrick's reading of the genre of horror, either through Literature, which provides him with the source for the script of his film, or through the dialogue with other cinematographic productions of the genre. From the tenets formulated by Fredric Jameson, Mikhail Bakhtin, as well as those by scholars of the director's work, such as Rasmussen, Mario Falsetto, Roberto Romano, Maria Sylvia Franco, among others, we observe that, through the meta-generic process - which deviates from a conventional attitude, by reflecting on that generic structure taken as the object -, as well as by recurring to an elliptical element, Kubrick proposes an innovation and a new sense to the genre.
\end{abstract}

Key words: Genre of horror; Gothic; Literature and cinema

\section{Introdução}

Um filme de horror cujas imagens predominantemente nos fascinam por uma clareza ilusoriamente apolínea. Não flagramos o uso de ângulos de câmera distorcidos tão comuns em filmes do gênero, seja no caso de um de seus precursores, como $O$ Gabinete do Doutor Caligari (1920, direção de Robert Wiene), seja em clássicos mais recentes, como Psicose (1960, de Alfred Hitchcock) —, ao contrário, no filme de Kubrick, percebemos enquadramentos precisos e equilibrados que, acompanhados do extenso uso de urna luz natural, "límpida" e fria, descrevem situações e cenários nítidos. A imagem de Apolo não é solicitada em vão: (aparentemente) a história dos Torrance se

\footnotetext{
${ }^{1}$ Universidade do Estado de Mato Grosso - Unemat; Campus universitário de Pontes e Lacerda - MT, Brasil; e-mail: helviomoraes@pq.cnpq.br.
} 
nos oferece de forma racional, rigorosamente iluminada, quase que inteiramente linear. Podemos dizer que temos aqui um foco narrativo que permanece friamente distante dos conflitos vividos pelas personagens, registrando com fidelidade e sem paixão cada momento desse "drama familiar" (de fato, é raro o uso da câmera subjetiva ${ }^{2}$ ).

Além disso, onde comumente se prevê a aparição do monstruoso ou da alteridade representada de forma caricata ou deformada, nos surpreendemos com urna imagem de urbanidade, do tratamento cortês e obsequioso, urna aparência de mundo que apequena ou que reduz à sujeição a personagem principal da trama, não por urna superioridade física, mas justamente por certa "excelência espiritual" que tal imagem evoca. Traídos pelas convenções do gênero, constatamos que o monstruoso está onde menos se espera: na vítima.

São estas as primeiras impressões que me instigam a buscar uma melhor compreensão da leitura que Kubrick faz do gênero do horror, seja na literatura, onde busca a fonte para o roteiro de seu filme, seja no diálogo que estabelece com outras produções cinematográficas do gênero. Mais especificamente: urna vez que, no nível da estrutura fílmica, percebemos desvios das regras comuns ao gênero, seja pela inusitada abordagem técnica, seja pela subversão de uma estrutura pré-determinada, tais desvios poderiam apontar para uma nova concepção do gênero do terror? Ou, seguindo a principal tendência da cultura de entretenimento, representariam apenas uma inovação contida somente no âmbito do aprimoramento tecnológico? ${ }^{3}$

I

Este método ou estilo empregado por Kubrick se vincula a uma tendência que Fredric Jameson, num conhecido estudo sobre o "Historicismo em O Iluminado", percebe nos artistas mais inventivos da contemporaneidade, tendência esta intimamente

\footnotetext{
${ }^{2}$ Técnica em que a câmera assume o ponto de vista de determinada personagem.

${ }^{3}$ De fato, em entrevistas concedidas no período de lançamento de $O$ Iluminado, Kubrick ressalta seu interesse em apenas produzir um filme de gênero. Falando a Vicente Molina Fox, numa entrevista de 20 de dezembro de 1980, o diretor destaca sua preocupação quanto ao êxito de seu trabalho no sentido de "bom entretenimento": "Creio que a inventividade de uma história como esta é algo que o público, no final das contas, aprecia". Jack Kroll (26 de maio de 1980) dirá que Kubrick "insiste em seu interesse pel'O Iluminado como um engenhoso exemplo do gênero de histórias de fantasmas", mas a seguir indica o que, como veremos, está realmente por trás de todo o projeto: 'Se você insiste em pressioná-lo [Kubrick] ("Você está me colocando contra a parede", ele diz), admite que há implicações mais profundas na história". Na entrevista em questão, Kubrick afirma seu desejo de explorar algo de errado que é inerente à personalidade humana. $\mathrm{O}$ "lado mau" ("evil side") da natureza humana é um dos temas mais recorrentes à sua cinematografia. Está nitidamente presente em filmes como Dr. Fantástico (1964) e Laranja Mecânica" (1971).
} 
relacionada ao conceito de pastiche. $\mathrm{O}$ autor segue a diferenciação proposta por Adorno entre pastiche e paródia,

pois esta pretende ridicularizar e depreciar estilos ainda vigentes e influentes. Embora o pastiche implique a existência daquela mesma distância que se mantém em relação ao instrumento ou à técnica artística acabada, ele pretende, mais precisamente a exemplo da imitação dos mestres antigos ou mesmo no caso da falsificação, revelar o virtuosismo do aprendiz [...] (Jameson, 1995, p. 84).

Para o teórico americano, o pastiche, no mundo pós-moderno, se origina do desgaste do individualismo (ou subjetivismo) - a singular expressão de um artista, corno fator preponderante para a apreciação da obra artística. A partir do momento em que "a mera diferença de individualidades idiossincráticas progressivamente transforma-se sob seu próprio impulso em repetição e mesmice" e as "permutações lógicas de inovação estilística se esgotam [...], artistas vigorosos, agora carentes de formas e conteúdo, canibalizam o museu e usam as máscaras de maneirismos extintos" (ibidem, p. 84-5).

No campo do cinema - e, neste ponto, por tratarmos de Kubrick, devemos pensar em Hollywood - , qualquer tentativa no sentido de uma "produção individual característica" é vetada pela indústria cinematográfica, que redireciona "essas energias para produções medíocres" (ibidem, p. 85), que são o que comumente se denomina como filmes de gênero.

Porém, também neste caso, temos um esgotamento, que se dá de maneira inversa ao que vimos acima. Enquanto na esfera da alta cultura é o "excesso de inovação" que se esgota, no campo do entretenimento de massa, o uso excessivo de determinadas estruturas estéticas e conceituais, características dos filmes de gênero, chega a um ponto de exaustão. Assim, uma vez que o cineasta enfrenta dificuldades em estabelecer um estilo inovador e próprio, no sentido das vanguardas modernas, e tampouco "é possível fazer um filme obedecendo às convenções do gênero no sentido tradicional" (Vugman, 2001), a solução encontrada é a reflexão, o dobrar-se sobre a estrutura genérica anterior, buscando apontar novas possibilidades de produção artística, o que Jameson chamará de produção metagenérica. A maioria dos filmes de Kubrick, Polanski, Altman e Roeg, são, para Jameson, filmes que 
utilizam uma estrutura predeterminada de gêneros herdados como um pretexto para uma produção que não é mais pessoal ou estilística no sentido anterior do modernismo. [A produção metagenérica] é geralmente descrita em termos de reflexibilidade, da auto-referencialidade e do debruçar da produção artística sobre seus próprios processos e técnicas (Jameson, 1995, p. 86).

O procedimento metagenérico também nos possibilita compreender melhor, seja como seu sintoma ou consequência, a ambiguidade consciente e voluntariamente explorada por Kubrick em seus filmes, o que, de fato, possibilita leituras tão díspares e provoca polêmicas tão acaloradas. Só mesmo numa abordagem temática capaz de fugir às determinações de uma estrutura tradicional, à revisitação de lugares comuns do gênero tomado como base, é possível observar o que eu aqui chamaria de elemento elíptico da narrativa kubrickiana. Como figura de linguagem, a elipse se define como a supressão, em um enunciado, de determinado termo, que, contudo, pode ser subentendido pelo contexto linguístico ou pela situação. Na obra cinematográfica, assim como na literatura, a elipse pode se dar com a omissão de uma informação ou de um fato que diz respeito a um ou mais elementos que compõem a estrutura narrativa: narrador, personagem, enredo, espaço e tempo. Se tal omissão for facilmente perceptível ou se o posterior desenvolvimento da narrativa possibilitar sua revelação de modo previsível, a obra artística tenderá a se circunscrever comodamente às determinações do gênero a que se liga. No caso em que a omissão não deixa "pistas" tão facilmente conducentes a uma interpretação unívoca, ou em que se percebe urna deliberada intenção por parte do autor/cineasta de gerar ambiguidade, teremos um exemplo de narrativa que tende a desestabilizar estruturas convencionais.

Portanto, obviamente encontramos exemplos da utilização da figura da elipse em vários textos e filmes, e até mesmo certos gêneros dela se valem de forma intensa, como se dá no caso das histórias de detetive. Contudo, a literatura de entretenimento e os filmes de gênero frequentemente a resolvem de forma convencional. Em várias produções literárias e cinematográficas de ficção científica, a trama se revolve em torno de se encontrar uma solução para uma situação anômala, que põe em risco a vida de uma comunidade ou da humanidade inteira. Uma vez descoberto o "antídoto", tudo volta ao normal. É o caso de algumas produções de M. Night Shyamalan, corno Sinais (2002) e O Fim dos Tempos (2008). 
O uso que Kubrick faz do elemento elíptico em $O$ Iluminado é, em minha opinião, seu recurso principal, capaz de encorajar uma multiplicidade de leituras, gerar ambiguidade e indicar um novo significado para o gênero do terror. É, ainda, o que mantém viva a sensação de temor toda vez que a ele retornamos. Neste sentido, concordo com Michael Dare quando afirma que $O$ Iluminado faz mais perguntas do que as responde, e que, enquanto "a maioria dos filmes de horror quase perde seu suspense quando assistidos pela segunda vez [...] porque sabemos onde estão todas as surpresas, [...] Kubrick fez um filme capaz de tornar-se mais assustador a cada vez que o assistimos", porque evita efeitos triviais do gênero. De fato, a atmosfera de terror se faz sentir desde a primeira cena e permeia toda a narrativa, não se colocando estrategicamente em determinados pontos com a finalidade de produzir urna espécie de susto gratuito. Porém, o que Dare deixa de perceber é que tal efeito também é obtido por meio de alguns silêncios na estrutura narrativa, assim como por certas inovações técnicas, que criam verdadeiros "enigmas" interpretativos, como a questão do foco narrativo a partir do posicionamento e movimentação da câmera em determinadas situações - basta pensarmos na sublime cena de abertura e nas cenas em que Danny circula pelos corredores do hotel em seu triciclo, momentos em que a câmera parece adquirir uma vitalidade anímica. Tais lacunas são dificilmente perceptíveis, pois, como afirmei no início, escondem-se por trás da suposta clareza e racionalidade do discurso cinematográfico kubrickiano, que se estende escorreito e linear.

Os êxitos do emprego deste artifício retórico se tornam mais nítidos quando comparamos o romance de Stephen King e o filme de Kubrick. O Iluminado de King é repleto de informações acerca da história familiar dos Torrance e reiteradamente elucida os motivos de suas ações e de seus receios. Não há verdadeiramente um lado obscuro na relação das três personagens centrais. Ao contrário, à medida que a leitura prossegue, apenas constatamos o que previsivelmente se enunciara em páginas anteriores. $\mathrm{O}$ passado turbulento da família é trazido de forma minuciosa, por meio de flachbacks. Jack, Wendy e Danny rememoram experiências amargas de um passado recente. Cada um ilumina um aspecto particular desta história, mas seus pontos-de-vista não se contradizem, antes, se harmonizam e nos apresentam um quadro bastante abrangente de seus conflitos íntimos e de sua relação familiar. Assim, logo nas primeiras páginas, sabemos que Jack é um pai amoroso e um esposo sinceramente empenhado em resolver seus problemas com Wendy. Seu temperamento irascível já o fizera perder o controle emocional algumas vezes, a última das quais lhe causou a perda do emprego como lluminado: o gênero do horror na leitura de Stanley Kubrick. -Helvio Moraes. p. 148 163. 
professor numa escola secundária - espancou um aluno. Danny se lembra a todo o momento de que o pai fazia "a coisa feia" - se embriagava todas as noites —, e que, numa destas circunstâncias, o agredira e lhe quebrara o braço. Mais um exemplo do descontrole emocional de Jack: o garoto havia espalhado pelo escritório as páginas de um texto que o pai estava escrevendo ${ }^{4}$. Wendy não consegue perdoar o esposo por isto e, juntamente com seu problema em relação à bebida, esteve várias vezes a ponto de propor a separação. Um período considerável de abstinência e as novas possibilidades trazidas pelo novo emprego de Jack, a fazem contemplar o Overlook Hotel com certa esperança 5 .

Nada disto é mencionado por Kubrick. Em seu lugar, sorrisos vazios, diálogos bastante corriqueiros, que apenas sugerem uma instabilidade, ou até mesmo distância, na relação entre pai/filho, homem/mulher. A omissão dos dados que King atentamente empenha-se em nos fornecer causa estes vácuos na narrativa aparentemente abarcante do filme e a torna muito mais densa. O terror não está, como em King, na superfície do que é funestamente previsível, mas, sim, numa força que se manifesta sem que saibamos com certeza de onde emana.

\footnotetext{
4"Tudo fora tão vagaroso quanto um sonho mau. Todas as portas e gavetas do escritório pareciam ter sido saqueadas em sua ausência. Armário, prateleiras, estante. Todas as gavetas arrancadas. O manuscrito da peça de três atos que vinha desenvolvendo devagar, com base numa novelinha que escrevera sete anos antes, quando ainda era estudante, estava espalhado pelo chão. Tomava uma cerveja e trabalhava na revisão do segundo ato, quando Wendy chamou-o para atender um telefonema. Danny entornara a cerveja em todas as páginas. Provavelmente para ver a espuma. [...] Tudo isso aumentava sua raiva. Deu um passo deliberado em direção ao filho de três anos, que o olhava com um sorriso de prazer; o prazer de haver concluído, com sucesso, um trabalho no escritório do pai; Danny dissera alguma coisa quando ele agarrou sua mão, dobrando-a para fazê-lo largar a borracha da máquina de escrever e a lapiseira. Danny gritou um pouco... não... não... diga a verdade... ele berrou. Era tudo muito duro para ser lembrado através de uma névoa de raiva, de uma corda partida. [..] Rodopiara Danny para espancá-lo; seus dedos grandes de adulto cavando a pele do braço da criança, apertando seu pulso. O estalar do osso quebrado não foi alto, não foi alto... foi muito alto, IMENSO. [...] Um momento de silêncio absoluto de u, lado, em respeito ao futuro que talvez estivesse começando agora." (King, s.d., p. 20-1).

${ }^{5}$ “E não sentia ela, por vezes, a oposição silenciosa do filho pela ideia do divórcio? Se estivesse pensando no assunto ao cortar as batatas para o jantar, ao voltar o rosto via-o sentado na cadeira da cozinha, de pernas cruzadas, olhando-a amedrontado e acusador. Passeando pelo parque, ele de repente agarrava suas mãos e perguntava... quase peremptório: "Você me ama? Você ama papai?" E ela, confusa, balançava a cabeça ou dizia: "Claro que sim, meu bem". [...] Havia ocasiões em que sua determinação em pelo menos discutir o assunto com Jack se desfazia, não por fraqueza, mas devido à vontade do filho. [...] Mas em sonhos acreditava, e em sonhos, com o sêmen do marido ainda secando em suas coxas, sentia que os três formavam um só corpo... e, se a trindade fosse desfeita, não o seria por nenhum deles, mas por algo exterior. A maior parte de suas crenças girava em torno de seu amor por Jack. Nunca deixara de amá-lo, a não ser talvez durante aquela fase negra que se seguiu ao "acidente"." (King, s.d., p. 59).
} 
A cena de abertura é, por si só, um perfeito exemplo do que acabo de afirmar. Dela, não encontramos um correlato no romance de King, que começa já com a cena da entrevista. Algo absolutamente livre, ágil e dotado de um grande poder irrompe na tela e nos oferece a visão que está tendo à medida que prossegue em seu voo solitário. É uma tomada de câmera subjetiva, pois escolhe livremente seu ritmo e sua direção, se aproximando ou tomando distância dos objetos que lhe interessam seguir ${ }^{6}$. Parece perscrutar o carro dos Torrance, minúsculo quando visto do alto, um ponto quase insignificante abrindo caminho entre a vegetação densa, o terreno inóspito e a superfície íngreme. Segundo Franco e Romano (1993, p. 37),

na paisagem majestosa, contrasta a finitude do homem. Visto à distância e do alto, o caminho por ele aberto entre os ermos sem fim se estende como um fio condutor, delgado e sinuoso, através de um labirinto. Simultaneamente a esse espaço onde se contrapõem as medidas entre a natureza e a humanidade, a música solene e grave modula o tempo que, em um só movimento largo e contínuo, envolve e conduz o todo formado pelo ambiente físico e cultural. Nesses quadros iniciais, tudo se move: montanhas, florestas, estrada, automóvel. chofer, tudo se anima e avança, conjuntamente, rumo a um fim, para um mundo gelado, tempestuoso, obscuro.

Os autores colocam em evidência um tema que será constante na filmografia de Kubrick: uma espécie de percurso que simultaneamente o mundo natural e o mundo humano realizam e que, de certa forma, cumpre um movimento que, numa noção aproximativa, denominaria como circular. Há um suceder-se de movimentos naturais que, embora provoquem alterações no mundo físico, inevitavelmente se repetem num fluxo temporal incessante, como o alternar-se das estações climáticas. Da mesma forma, a história humana registra uma alternância de movimentos, embora seja a escrita da luta

\footnotetext{
${ }^{6}$ Em nenhum momento desta cena de abertura a câmera nos fornece o ponto-de-vista de Jack, enquanto dirige. De fato, o tratamento do ponto-de-vista da câmera no filme é bastante elucidativo tanto aqui como em outras partes. Kubrick evita posicionar a câmera a partir do ponto-de-vista das personagens. $\mathrm{O}$ único exemplo de tomada de câmera numa perspectiva subjetiva (da personagem) talvez sejam as visões de Danny e, com certeza, o momento em que ele adentra o quarto 237. Isto é relevante principalmente para urna leitura das cenas em que Jack encontra-se no Golden Ball Room: os fantasmas que ele vê são manifestações de sua mente ou são produzidos por algum agente que se encontra por perto? O diretor não nos fornece a imagem de Lloyd, o barman, a partir do campo de visão de Jack, parecendo que existe ali urna presença misteriosa que assiste à conversa dos dois personagens. Algo parecido acontece com Wendy, enquanto sobe as escadas tentando se desvencilhar de Jack.
} 
do homem contra a ciclicidade da natureza. A cultura abre um caminho sinuoso e estreito em meio às forças naturais, mas ela é calcada na violência, e não raro acontece urna espécie de regressão à barbárie. Esta concepção da vida humana pode ser observada já nos primeiros filmes do cineasta, inseridos no âmbito de uma estética noir. No entanto, se mantém ao longo de sua carreira, até mesmo em produções como a comédia de humor negro Dr. Fantástico, em que se percebe "uma sombria visão do destino humano e uma sensação do homem como vítima de forças que ele é incapaz de controlar"7 , consideração que, obviamente, pode se estender também ao seu filme de terror.

Assim, n'O Iluminado, "as Rochosas, em seu belo revestimento outonal fadado ao mais rude inverno, são percorridas por alguém igualmente preso a um destino impiedoso" (ibidem, p. 38). Desde Shakespeare, sabemos que esse "destino impiedoso", pelo menos no âmbito das questões humanas, é consequência das próprias ações humanas. O destino de Jack Torrance é o Overlook ${ }^{8}$ Hotel, imagem que, em sua imponência, concentra uma sucessão de tempos da história americana, e que será o enorme calvário emocional dos Torrance, assim como o fora a nave Discovery para os astronautas de 2001: Uma Odisseia no Espaço (cf. Rasmussen, 2005, p. 232). Simultaneamente, símbolo de um passado glorioso, de urna civilização decadente e de um sonho vazio, o Overlook se encontra no ponto mais alto da estrada serpejante.

\section{III}

O Overlook é uma reelaboração da imagem da casa abandonada e malassombrada, elemento tradicional da literatura gótica ${ }^{9}$. Alguém ou alguma situação se

\footnotetext{
${ }^{7}$ Hirsh apud Philips \& Hill (2002, p. 115).

${ }^{8}$ O termo "overlook" tem várias acepções: como substantivo, pode significar "mirante", um lugar elevado capaz de propiciar uma boa vista; como verbo, pode ter um sentido semelhante, "fornecer urna determinada vista, especialmente de um lugar elevado" (note-se que é exatamente o que a câmera faz na cena inicial -- alguns autores relacionam esse posicionamento da câmera com o próprio Overlook); uma outra acepção é de "passar por alto, não perceber" algo que está presente em uma situação.

${ }^{9} \mathrm{Da}$ mesma forma, $O$ Iluminado "marca o retorno e a reinvenção de um subgênero muito mais velho [que o novo gênero do filme do sobrenatural], com suas leis e conteúdos específicos, a saber, o subgênero da história de fantasmas" (Jameson, 1995, p. 92). Esta distinção é muito importante, principalmente para a leitura que proponho, pois indica urna nova chave interpretativa. O moderno gênero do sobrenatural nos apresenta histórias de possessão demoníaca, algo que esperávamos fosse acontecer com Danny, logo nas cenas iniciais. À medida que o filme prossegue, percebemos que "estávamos procurando pela mensagem no lugar errado: em vez do garotinho, "possuído", de algum modo sinistro, pelo seu espectral companheiro de brincadeiras, é o pai [...] e sua fraqueza que abrem um vácuo para o qual vertem todos os
} 
estabelece onde não devia. O caso em questão é uma variante de um topos de várias histórias de horror (basta pensarmos em "A Queda da Casa de Usher" (1845), de Edgar Allan Poe, na literatura, e Poltergeist (1982), no cinema): o mundo civilizado, simbolizado por um edifício solidamente construído, é abalado pela violação de alguma lei sagrada (o sepultamento em vida, a construção sobre um cemitério, etc). O Overlook foi construído sobre um "cemitério indígena e chegaram a repelir alguns ataques indígenas durante a construção" ${ }^{10}$. Outro possível truque do diretor, criando urna expectativa num ponto onde será frustrada. Um aficionado de filmes de terror possivelmente espera que uma consciência índia ancestral se revivifique e busque a vingança pela violação de suas leis sagradas. É verdade que a presença de elementos da cultura indígena norte-americana faz-se perceber pelos corredores e salas do hotel, corno no imenso painel do Salão Colorado (onde Jack "escreve"), nas estampas e motivos dos tapetes que cobrem o piso dos corredores, no vestuário e no penteado de Wendy ${ }^{11}$. Na trilha sonora, percebemos o som de tambores, que parecem marcar o compasso de um ritual indígena, e na música de abertura ouvem-se gritos tribais. Porém, mais do que incorporar uma força destruidora, tais elementos testemunham urna derrota, mas uma derrota que dá fundamento e deixa marcas que se inscrevem nas paredes e pisos desta magnífica construção. Concordo, portanto, com Franco e Romano (1993, p. 40), quando afirmam que nesses detalhes se encaixam

um dos conflitos raciais básicos da civilização americana, com a guerra e domínio pelo homem branco. Sem valorizar essa predominância como nos épicos do faroeste, nem criticá-la como nas recentes revisões do gênero, Kubrick as coloca lá, como uma das pedras fundamentais do edifício, registro do acervo cultural e da ordem sociopolítica americana.

tipos de impulsos maléficos inicialmente indeterminados" (idem). Passemos ao largo da asserção de Jameson de que até mesmo esta imprecisão quanto ao gênero em questão faz parte da reflexividade da obra metagenérica. Conforme as regras do gênero mais antigo, o elemento sobrenatural se defronta com o humano, o apavora, mas não há uma possessão. A diferença é sutil, mas, aqui, fundamental: Jack não é "possuído", mas "assombrado". Esta perspectiva amplia nossa compreensão do procedimento utilizado por Kubrick em relação ao posicionamento da câmera.

${ }^{10}$ Fala de Ullman, o gerente, enquanto mostra as dependências do hotel ao casal de "zeladores". Segundo Rasmussen (2005, p. 245), "sua maneira casual reduz uni outrora ardente conflito cultural a uma trivial nota de rodapé da história".

${ }^{11} \mathrm{O}$ ardil usado por Danny para escapar da perseguição do pai é um truque indígena. Os nativos, para despistar as tropas do exército americano, voltavam sobre suas próprias pegadas e tomavam um novo rumo, deixando, assim, o inimigo desorientado. 
É pertinente lembrarmos, por fim, nestas referências ao gótico, que a imagem do imponente edifício em que se enclausuram os Torrance pode ser esclarecida também à luz das considerações que Bakhtin apresenta em relação ao cronotopo do castelo. Segundo o teórico russo, tomando por base os romances de Walpole e Radcliffe,

O castelo está repleto de tempo, que por sinal é histórico no exato sentido da palavra, ou seja, o tempo do passado histórico. O castelo é o lugar onde vivem os senhores feudais (por conseguinte, também as figuras históricas do passado), as marcas dos séculos e das gerações estão depositadas sobre várias partes do edifício, no mobiliário, nas armas, na galeria de retratos dos ancestrais, [...] nas relações humanas específicas da sucessão dinástica, da transmissão dos direitos hereditários. Enfim, as lendas e as tradições revivem, pelas recordações dos acontecimentos passados, todos os recantos do castelo e das cercanias. [...] O castelo veio dos séculos passados e está voltado para o passado (BAKHTIN, 2010, p. 351-2).

O Overlook serve muito bem à perspectiva de uma releitura do cronotopo do castelo. Nos corredores e aposentos desta magnífica construção também se concentram e se sobrepõem vestígios de outras formações culturais, das mais variadas épocas. $\mathrm{Na}$ versão mais longa do filme, anterior à edição que aqui tomo como meu objeto de estudo, Ullman faz questão de mostrar a Jack e Wendy (e, obviamente, a nós) todas as dependências do hotel, situação também que permite dar a conhecer um pouco de sua história. Além das fotos sobre as paredes e da reforma do salão de bailes ao estilo dos anos 20, somos informados que, em seu auge, o hotel recebia o jet set americano (expressão cujo anacronismo é imediatamente reconhecido pelo próprio gerente), além de ter dado hospedagem a quatro presidentes da república. É bastante provável que Kubrick tenha percebido posteriormente a redundância de algumas destas cenas, tanto que as descarta na edição final. É óbvio que aquele resort não é destino para as férias de famílias como os Torrance, e que o lugar já teve seu apogeu fica evidente na parte final do filme. No entanto, a bandeira americana, seja em miniatura sobre a mesa do gerente, seja em tamanho natural sobre a mesa em que Jack trabalha, evidencia ainda a presença maciça de uma configuração social que se plasmara por meio de um sonho, um mundo em que Jack vagueia como um pária.

Todas estas referências, todos estes elementos culturais característicos da história americana se contrapõem ao vazio e ao silêncio que se instauram no momento 
em que a família se vê só. Jack é esse vazio, esse silêncio entre sua família e a arquitetura sólida do hotel. Buscando rompê-los, produz barulho com uma bola de tênis arremessada contra as paredes, teto e piso do Salão Colorado, datilografa de forma incessante a mesma frase. Seu esforço é vão.

Como zelador, espera-se de Jack que consiga manter intacta a grande estrutura que lhe foi confiada. Como marido e pai, dele se espera que seja o que é o marido e pai de uma família de classe média: sustento. Frustra ambas expectativas.

Indícios de que seu mundo familiar lhe parece causar certa aversão, encontramos logo nas primeiras cenas. Rasmussen (2005, p. 237) chega a afirmar que, em contraste com a cena do Overlook, em que Jack parece se sentir completamente à vontade no ambiente luxuoso em que se encontra, a cena do apartamento do casal em Boulder "discretamente prepara o terreno para a violenta rejeição de Jack em relação a Wendy, Danny e Boulder, em favor do Overlook e de seu passado fantasmagórico". De fato, nesta cena encontramos alguns elementos que serão retomados posteriormente, ante os quais observaremos uma atitude de repulsa por parte de Jack. A simplicidade do ambiente, à qual se adéqua a simplicidade — quase simploriedade — de Wendy, será definitivamente contrastada com o delírio de grandeza do marido no Golden Room, mas também com a ilusão da nobreza do oficio de escritor - um espaço que ele categoricamente nega a Wendy. A mulher e a criança encontram-se na cozinha, que é também o lugar que o Overlook parece querer lhes reservar (juntamente com o cozinheiro negro). Mais interessante, porém, nesta cena está inserido o tema da presença da televisão na formação da classe média americana, algo que será reiteradamente ridicularizado por Jack: Danny assiste a um cartoon, o Papa-léguas - não por acaso, uma série de desenhos animados em que um coiote incessante e incansavelmente procura capturar e devorar um galo-corredor. ${ }^{12}$

A cena em que os Torrance estão a caminho do Overlook é construída de forma magistral. Numa conversa trivial, Kubrick insere motivos cujos sentidos irão se consolidando e alargando à medida que forem sendo retomados ao longo da narrativa. Wendy percebe que, nas alturas, a mudança atmosférica afeta os sentidos. Logo a

\footnotetext{
${ }^{12}$ Palmer (2007, p. 208) segue esta mesma orientação: "As sequências que abrem o filme sugerem fortemente a insatisfação de Jack com seu quinhão da vida, especialmente sua falta de afeto por Wendy e Danny, a quem vê corno impedimentos à sua liberdade e auto-realização. Sua interação com o mundo dos espíritos nada mais faz do que confirmar seu ressentimento enraivecido pelas demandas da família e até mesmo pela sua presença".
} 
seguir, alude a um terrível capítulo da história americana, em que um grupo de colonizadores "dos tempos das carruagens", perdidos em alguma daquelas montanhas, se veem obrigados a recorrer ao canibalismo como forma de sobrevivência. Danny quer compreender melhor o que aconteceu aos colonizadores e o pai lhe explica de forma direta e clara, com um semblante que não esconde a satisfação em tocar neste tipo de assunto. Wendy suavemente o recrimina por ter exposto ao filho algo tão horrendo. $\mathrm{O}$ filho busca confortar a mãe, porque já havia aprendido tudo sobre canibalismo por meio da TV, o que provoca uma reação irônica de Jack: "Viu? Não tem problema. Ele viu na televisão".

Nas cenas seguintes, em que os Torrance não estão sós, percebe-se que cada vez mais se alarga o abismo que separa Wendy e Danny de Jack. O ponto culminante se dá na cena em que Wendy procura dar conforto ao marido, recém-despertado de um pesadelo, e Danny adentra o salão em estado de choque, após ter sido molestado pela figura de uma estranha mulher no quarto 237. Percebendo o estado do filho e notando algumas escoriações em seu pescoço, Wendy acusa o marido de ter provocado tais ferimentos. Rompem-se os já tênues laços familiares e Jack se entrega definitivamente aos fantasmas do hotel, nas cenas que se passam no Gold Room.

Num gesto que evoca o mito do Doutor Fausto, Jack vende sua alma: "Daria tudo por um drinque". Imediatamente, Lloyd, o barman, surge à sua frente, e lhe satisfaz o desejo. Jack quer pagar, mas, como sua carteira está vazia, é informado que tem crédito na casa. Somente em frente aos fantasmas, ele externa seu pensamento.

Portanto, é num ponto já avançado da história que teremos uma melhor compreensão das angústias que afligem o protagonista, quando finalmente nos permite ter acesso ao seu mundo interior (cf. Falsetto, 2001, p. 127). Alude, com um tom de amargura, ao acidente em que quebrara o braço de Danny - como vimos, um dado que King nos fornece logo nas primeiras páginas do romance —, e culpa Wendy por nunca deixá-lo esquecer do fato. Mais tarde, quando retorna ao salão, agora repleto de fantasmas que revivem o esplendor fitzgeraldiano da década de vinte, Lloyd reafirma que seu dinheiro nada vale ali, mas que pode beber o quanto quiser, pois essas são as "ordens da casa". Segundo Rasmussen (2005, p. 267), a partir deste ponto, a "Casa" começa a ditar os termos da fantasia de Jack. Sorve, então, um gole de bourbon, a que 
chama de "white man's burden" — o fardo do homem branco ${ }^{13}$ —, uma alusão à "correção" que terá que aplicar à sua família, mas que, até o momento, ignora. Disposto a aproveitar a festa, o pária da era Ronald Reagan - no entanto, Mr. Torrance para os fantasmas que o assombram —, trajando uma jaqueta surrada e com os cabelos desalinhados, passeia em meio a uma elegante multidão de espectros de uma "época de ouro", até se chocar acidentalmente com um garçom, que o leva ao banheiro masculino.

Num fascinante jogo de inversões sustentadas pela alternância da câmera em ângulos de 180 graus, observamos, finalmente, o encontro e identificação entre os "zeladores". O garçom é Delbert Grady, o antigo zelador que, em 1970, assassinara sua família e depois cometera suicídio. A cena é construída com primor: os atores são cuidadosamente posicionados de forma a criar a impressão de que Jack, ao conversar com Grady, na verdade, fala consigo mesmo através do espelho ${ }^{14}$. E, de fato, a terrível revelação acontece: "você sempre foi o zelador".

Como único e solitário zelador desta grande estrutura, sob pena de causar-lhe algum dano, Jack não pode permitir que seu filho ali introduza uma pessoa estranha "an outside party"15 —, um outsider, alguém que não participa da festa que ininterruptamente se estende no Golden Room: "um negro, um cozinheiro negro". Mais uma vez, todo um passado de violência racial irrompe no presente e, neste turbilhão, são arrastadas também a criança e a mulher, "the outside party", aqueles a quem o homem branco deverá corrigir: este é seu fardo.

Conhecemos o fim da história: Danny, por meio de seus poderes especiais, consegue se comunicar com Halloran, o cozinheiro negro, que parte imediatamente em seu socorro, trazendo para o hotel o instrumento que mãe e filho precisam para fugir da fúria de Jack. Halloran, contudo, pelo "serviço" prestado, recebe a morte pelas mãos do “zelador". Este, ao perseguir o filho, adentra o labirinto construído nos fundos do hotel

\footnotetext{
13“"White Man's Burden” é o título de um poema de Rudyard Kipling, escrito em 1889, visto por muitos estudiosos como um manifesto a favor da tendência imperialista dos Estados Unidos, quando da conquista das Filipinas e outras colônias espanholas. Uma estrofe do poema diz- "Aceitai o fardo do homem branco / Enviai os melhores homens que criais / Ide, obrigai vossos filhos ao exílio / Para servirem às necessidades de vossos cativos / Para atenderem, numa armadura pesada / O povo tremulante e selvagem, / Seu povo recém-conquistado e taciturno / Metade demônio e metade criança".

${ }^{14} \mathrm{Na}$ verdade, há sempre um espelho nas cenas em que Jack conversa com um fantasma (ou se encontra com um, como é o caso da moça/velha do quarto 237). Contudo, cabe salientar mais uma vez que a posição da câmera pode sugerir que os fantasmas são, antes de tudo, uma criação do hotel que, neste caso, assume um dos papéis principais da narrativa. A este propósito, ver Falsetto (2001, p. 127).

${ }^{15}$ O substantivo "party", além de partido político, tem a acepção de uma das pessoas ou grupo de pessoas envolvidos numa questão oficial ou situação semelhante.
} 
e lá se perde, morrendo congelado. Wendy e Danny conseguem escapar, deixando o hotel e penetrando, com o snowcat, um cenário desolador que não nos convence completamente sobre a chegada dos dois a um local seguro.

Numa das paredes do hotel, resta uma imagem congelada de Jack, "Mr. Torrance", que aparece feliz e elegante na fotografia do baile de 4 de julho de 1921. Com ela se contrasta o busto de Jack congelado no labirinto. Segundo Franco e Romano (1993, p. 54), o "retrato reúne várias pessoas em torno do signo máximo da cultura americana - o 4 de julho - e consolida a figura do "caretaker", encarnação desse mundo, que atravessa e ressurge, revivificado, nos anos 80".

Algo parecido dirá Jameson (1995, p. 93), para quem

o Jack Nicholson de $O$ Iluminado não está possuído pela maldade em si nem pelo "demônio" ou alguma força oculta semelhante, mas simplesmente pela História, pelo passado americano, que deixou seus vestígios sedimentados nos corredores e nas suítes desmembradas desse asfixiante edifício monumental, que projeta sua pós-imagem formal e vazia no labirinto externo.

Seria possível atenuar essa imagem tão pessimista recorrendo à ideia de que o filho, o sobrevivente desse sonho hediondo, possa representar um novo tipo humano? Este homem nascido da experiência traumática de ser obrigado a matar seu próprio pai, dotado de um poder especial de perscrutar no futuro sinais que o auxiliem a agir no presente, que se aventura pela noite tempestuosa deixando às suas costas o sólido edifício construído por seus ancestrais, será ele um novo homem? O rosto de Danny, neste caso, tem uma relação direta com o rosto da Star Child ao final de 2001?

Ou será Danny o futuro zelador? Ao contrário da obra que lhe serviu de base para sua "adaptação", Kubrick não destroi o Overlook. Em King, o hotel é reduzido às cinzas. N'O Iluminado, ele permanece intacto, um contorno imponente e sombrio resistindo aos rigores da nevasca. Parece estar somente à espera de uma nova temporada, e uma nova temporada, e uma nova temporada, até que um Torrance ressurja no hall de entrada, à procura do emprego de zelador, ainda que a última cena nos mostre um hotel que, definitivamente, encerrou suas atividades. Lençóis brancos cobrem todos os móveis. 
Kubrick não nos responde ${ }^{16} \mathrm{e}$, de fato, não parece ser possível encontrar uma resposta unívoca para estas cenas finais. Mas é justamente esta uma postura própria da obra metagenérica, com sua capacidade de gerar ambiguidade a partir do uso da elipse.

\section{Agradecimentos}

Agradeço à professora Dâmaris de Oliveira pela recuperação da versão original deste texto.

\section{Referências}

BAKHTIN, Mikhail. Questões de Literatura e de Estética - A teoria do romance. São Paulo: Hucitec Editora, 2010.

DARE, Michael. "Kubrick, King, and the Ultimate Scare Tactic". The Kubrick Site. Disponível em: www.visual-memory.co.uk

FALSETTO, Mario. Stanley Kubrick: a Narrative and Stylistic Analysis. West Port: Praeger Publishers, 2001.

FRANCO, Maria Sylvia C. \& ROMANO, Roberto. "O Iluminado de Stanley Kubrick" in Leitura: Teoria e Prática, $\mathrm{n}^{\circ}$ 21. Porto Alegre: Editora Mercado Aberto, 1993.

JAMESON, Fredric. "Historicismo em O Iluminado" in Marcas do Visível. Rio de Janeiro: Graal, 1995.

KING, Stephen. O Iluminado. Rio de Janeiro: Editora Objetiva, 2005.

KROLL, Jack. "Stanley Kubrick's Horror Show". Disponível: www.archiviokubrick.it KUBRICK, Stanley. "David W. Griffith and His Wings of Fortune" in DGA Magazine, jun. 1997.

KUBRICK, Stanley. An Interview with Stanley Kubrick, Director of Lolita. New York, 1962. Entrevista concedida a Terry Southern. Disponível: www.terrysoiithern.com KUBRICK, Stanley. An Interview with Stanley Kubrick. El Pais - Artes, dez. 1980. Entrevista concedida a Vicente Molina Foix. Disponível: www.archiviokubrick.it KUBRICK, Stanley. L'intervista. Le petit livre de Stanley Kubrick, SpartOrange, 1994. Entrevista concedida a Jean-Marc Boineau. Disponível: www.archiviokubrick.it KUBRICK, Stanley. The Film Director as Superstar: Stanley Kubrick. Doubleday Company: Garden City, New York, 1970. Entrevista concedida a Joseph Gelmis. Disponível: $\underline{w w w . a r c h i v i o k u b r i c k . i t}$

OLALQUIAGA, Mayra Helena Alves \& DINIZ, Thaïs Flores Nogueira. "Texto e Imagem: The Shining e a Adaptação Kubrickiana" in Vertentes, São João del-Rei, ${ }^{\circ} 23$, jan./jun. 2004.

\footnotetext{
${ }^{16}$ Ao longo da leitura de algumas entrevistas, foi possível perceber uma atitude de evasão do diretor quando instado a se pronunciar em relação a alguma cena ou algum ponto polêmico de um filme. Numa entrevista concedida a Joseph Gelmis, em 1970, o sentido de tal postura torna-se claro: "[...] um certo grau de ambiguidade é válido, porque permite que o público "preencha" a experiência visual por si mesmo. De qualquer forma, urna vez que você trabalha num nível não verbal, a ambiguidade é inevitável. Mas é a ambiguidade de toda arte, de uma bela peça musical ou de uma pintura — você não precisa de instruções escritas do compositor ou do pintor acompanhando tais trabalhos de forma a "explica-los". [...] Reações à arte são sempre diferentes porque são sempre profundamente pessoais."
} 
PALMER, R. Barton. "The Shining and Anti-Nostalgia" in ABRAMS, Jerold J. (ed.). The Philosophy of Stanley Kubrick. Lexington, Kentucky: The University of Kentucky Press, 2007.

PHILIPS, Gene D. \& Hill, Rodney (ed.). The Encyclopedia of Stanley Kubrick. New York: Facts on File, 2002.

RASMUSSEN, Randy. ““The Shining”: Unsympathetic Vibrations” in Stanley Kubrick: Seven Films Analyzed. Jefferson, North Carolina: McFarland \& Company, Inc.: 2005. VUGMAN, Fernando S. "O Iluminado, de Stanley Kubrick". Atas do XXIV Congresso Brasileiro de Comunicação. Campo Grande/MS, Setembro, 2001.

FILMES:

HARLAN, Jan. Stanley Kubrick: A life in Pictures. [Filme - DVD]. Acervo Pessoal. KUBRICK, Stanley. 2001: Uma Odisséia no Espaço. [Filme —DVD]. Produção e direção de Stanley Kubrick. Manaus: Microservice Tecnologia Digital da Amazônia, 2005. 1 DVD, 149 min. color. son.

KUBRICK, Stanley. O Iluminado. [Filme-DVD]. Produção e direção de Stanley Kubrick. São Paulo: Abril, 2008. 1 DVD, 119 min. color. son. 